Letters to the Editor

\title{
Thermoenergetic Identification of Enantiomeric Isomers of Amino Acids
}

\author{
Shizuo Fujiwara and Yuko Nishimoto \\ Department of Chemistry, Faculty of Science, Kanagawa University, Tsuchiya, Hiratsuka 259-12, Japan
}

\begin{abstract}
Keywords Enantiomeric isomer, amino acid, nuclear magnetic resonance spectrometry, differential scanning calorimetry, sodium chloride, eutectic compound
\end{abstract}

It has recently been found by the present authors that the eutectic compound of sodium chloride and water, $\mathrm{NaCl} \cdot 2 \mathrm{H}_{2} \mathrm{O}$, forms an adduct with oxygen. ${ }^{1}$ The melting points of the eutectic compound and its oxygen adduct have been measured as $-21.7^{\circ} \mathrm{C}$ and $-22.3^{\circ} \mathrm{C}$, respectively. The value of melting of the eutectic compound which has been referred to in the literature ${ }^{2}$, $-22.3^{\circ} \mathrm{C}$, must be attributed to the oxygen adduct. When the salt concentration is as low as around $0.1 \mathrm{~mol}$ $\mathrm{NaCl} / 1$, the two phases of the eutectic compound, with and without oxygen, coexist in the sample: they are not mixed with each other although they are molten. The latter fact may be interpreted in terms of the concept of the "molecular space"."

Do the enantiomeric isomers of the amino acid behave differently from each other when they are in association with the eutectic compound which is confined in the "molecular space" of the salt ions? The question is important because the critical concentration of the "molecular space" is $0.1 \mathrm{~mol} \mathrm{NaCl} / \mathrm{l}$, which is almost equal to the salt concentration of the human blood, which is also that of the physiological saline water for mammals.

Accordingly, measurements have been made by differential scanning calorimetry, DSC, and by nuclear magnetic resonance spectrometry, NMR, on the aqueous sodium chloride solutions of $0.1 \mathrm{~mol} \mathrm{NaCl} / 1$, to which about $2 \mathrm{mmol} / 1$ amino acid has been added. The apparatus and the conditions of measurement are the same as those given in the former report. ${ }^{1}$ Namely, the sample solution has been held at $-60^{\circ} \mathrm{C}$ and warmed up at a rate of 1 degree per min. During the course of heating, the DSC measurement has been made on the sample. With NMR, the sample which had been frozen at $-60^{\circ} \mathrm{C}$ was placed at $-20^{\circ} \mathrm{C}$ and the proton resonance was measured. As seen in Figs. 1, 2 and 3, the feature of the results of measurements is, except for one point which will be referred to later, the same as that of the samples with no amino acids: the no-oxygen sample, which holds actually $0.7 \mu \mathrm{gO}_{2}$ per $\mathrm{ml}$ of the sample solution, presents a single line of DSC at $-21.7^{\circ} \mathrm{C}$ and the sample which holds oxygen, which is actually the air-saturated case which holds $8.7 \mu \mathrm{gO}_{2}$ per $\mathrm{ml}$ of the sample solution, presents a doublet of two peaks at $-22.3^{\circ} \mathrm{C}$ and $-21.7^{\circ} \mathrm{C}$. The record of NMR of the no-oxygen sample gives a single line and that of the oxygen-carrying sample gives a signal with two lines overlapping.

The exceptional point which has been cited above is also seen in Fig. 1. The sample with the L-form threonine presents a single line of melting at $-21.7^{\circ} \mathrm{C}$ regardless of the coexistence of oxygen. But the sample with D-form amino acid has shown a doublet when oxygen coexists, while, it presents a single line when oxygen is not present. Importantly, furthermore, the NMR signals of the molten eutectic compound have shown that when oxygen is copresent and the salt concentration is lower than ca. $0.1 \mathrm{~mol} \mathrm{NaCl} / 1$, the sample with $\mathrm{D}$-threonine gives a signal of two overlapped lines, and gives a single line when oxygen is removed. But the sample of L-threonine gives a single line regardless of the presence of oxygen.

Particular attention must be called to the NMR signal in which two component lines overlap. The NMR spectrum ${ }^{1}$ reveals the fact that the two component species of compound with melting points of $-22.3^{\circ} \mathrm{C}$ and $-21.7^{\circ} \mathrm{C}$ are not mixed with each other, but remain as separate phases in spite of the fact that they are in the molten condition. Since the discovery of the $D$ and $\mathrm{L}$ enantiomeric isomers of tartrate by Pasteur, no artificial synthetic method has ever succeeded in the production of either one of the isomers separately. The artificial method of preparation of amino acid produces only racemic compounds. This may be due to the fact that the arificial method of synthesis is not fine enough for identification of the thermoenergetic difference between the isomers. Hence it cannot control the individual reaction of each of the isomers separately.

Our results of the DSC measurements allow evaluation of the latent heat of melting, $\Delta H$. The $\Delta H$ 's of the eutectic compound and the oxygen adduct for $0.1 \mathrm{~mol}$ $\mathrm{NaCl} / \mathrm{l}$ solution are measured as 47 and $52 \mathrm{~kJ} / \mathrm{mol}$ 


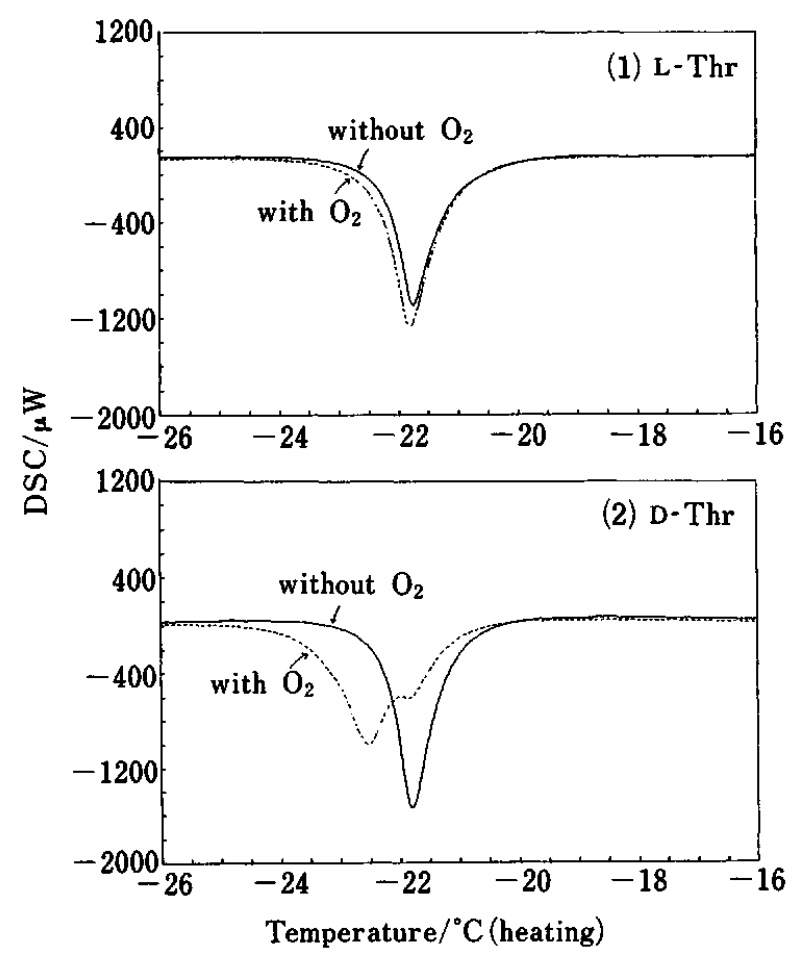

Fig. 1 DSC records of melting of eutectic compounds for the salt solutions of $0.10 \mathrm{~mol} \mathrm{NaCl} / 1$ in coexist of $2 \mathrm{mmol}$ L-threonine/l (l) and D-threonine/l (2).

$\mathrm{NaCl}$, respectively. The $\Delta H$ for the sample which carries $2 \mathrm{mmol} / \mathrm{l}$ D-form threonine is $43 \mathrm{~kJ} / \mathrm{mol} \mathrm{NaCl}$ and that of $\mathrm{L}$ is $37 \mathrm{~kJ} / \mathrm{mol} \mathrm{NaCl}$. The former value is the $\Delta \boldsymbol{H}$ for the doublet signal of the oxygen adduct as a whole. These results suggest that about $6 \mathrm{~kJ} / \mathrm{mol}$ $\mathrm{NaCl}$ difference exists between the $\Delta H$ 's for the $2 \mathrm{mmol} / \mathrm{l}$ solutions of $\mathrm{D}$ and $\mathrm{L}$ isomers which are in association with the oxygen adduct of the eutectic compound. The same results have been obtained with aspartic acid. The observed fact cited above may explain why the peptides or the proteins in nature are mainly formed of the L-form amino acids. For the latter, we must assume that the intermolecular associations which work in the melt in the frozen samples still hold in the solutions at room temperature.

For elucidation of the experimental findings shown above, efforts will be continued. This present note only states that an analytical method for thermoenergetic identification of enantiomeric isomers of amino acids seems to have been achieved.

\section{References}

1. S. Fujiwara, Y. Nishimoto, Anal. Sci, 6, 771 (1990).

2. "Gmelins Handbuch der Anorganischen Chemie", 8 Auf. System Nr. 21, S. 332 (1928).

3. S. Fujiwara, K. Nagashima, H. Morita and Y. Kanaoka, Bull. Chem. Soc. Jpn., 50, 2851 (1977).

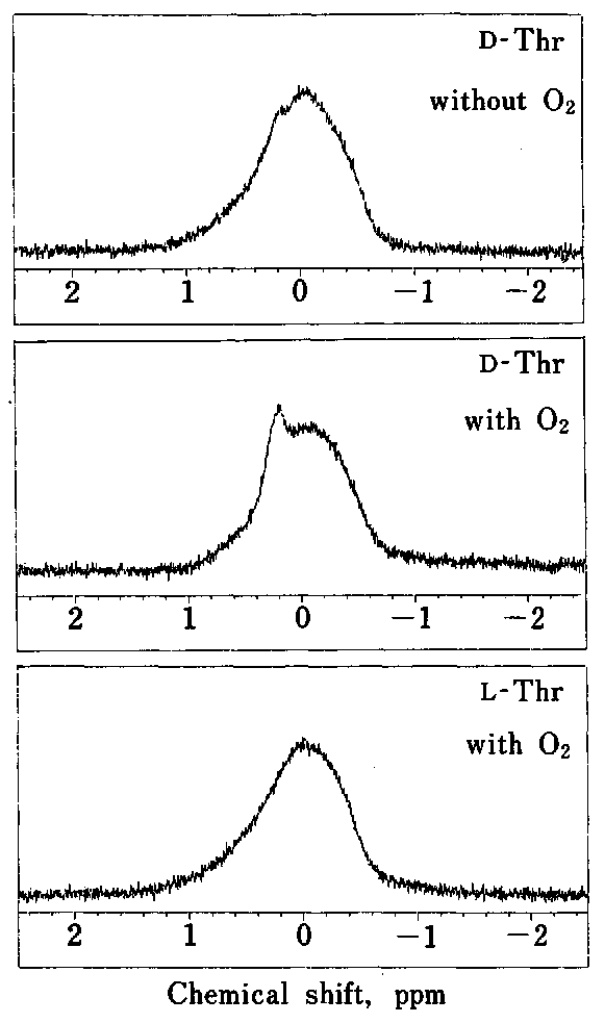

Fig. $2 \mathrm{NMR}$ records at $-20^{\circ} \mathrm{C}$ for the salt solutions of $0.10 \mathrm{~mol} \mathrm{NaCl} / 1$ and $2 \mathrm{mmol}$ threonine/1.

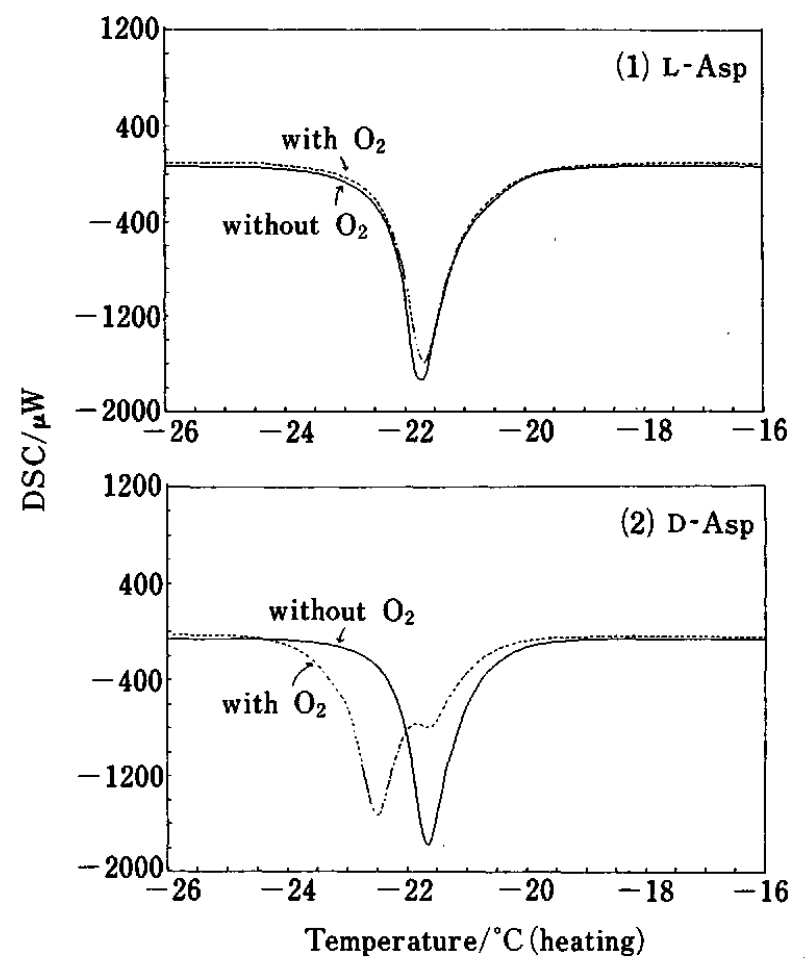

Fig. 3 DSC records of melting of eutectic compounds for the salt solution of $0.10 \mathrm{~mol} \mathrm{NaCl} / 1$ coexcisting with $2 \mathrm{mmol}$ L-aspartic acid/l (1) and D-aspartic acid/l (2).

(Received August 27, 1990) (Accepted September 13, 1990) 